\title{
sciendo
}

\section{How Friendship doesn't Contribute to Happiness: A Reply to Leibowitz}

Diana Sofronieva

Independent researcher

\begin{abstract}
Friendship and happiness are intimately connected. According to a recent account provided in Leibowitz (2018) friendship contributes to happiness because friends value each other and communicate this valuation to each other, which increases their self-worth, and this in turn increases their happiness. In this paper I argue that Leibowitz's account of how friendship contributes to happiness is mistaken. I first present Leibowitz's view, and then argue against it. I have two main worries with his account. One worry is that increase in self-worth is not characteristic of friendship and hence it is problematic to use it for explaining the connection between friendship and happiness. The other worry is that the distinctive way in which increase in self-worth contributes to happiness seems to be in an important way different from the distinctive way in which friendship contributes to happiness. Finally, I point to what I take to be the right direction in explaining the connection between friendship and happiness.
\end{abstract}

Keywords

Friendship, happiness, self-worth, intrinsic value, instrumental value.

\section{Introduction}

Friendship and happiness are intimately connected. Friendship tends to increase our happiness, and many of us would think that one cannot be truly happy without friendship (Sherman 1993). A recent paper by Leibowitz attempts to explain the intimate connection between friendship and happiness. According to the account provided in this paper, friendship contributes to happiness because friends value each other and communicate this valuation to each other, which increases their self-worth, and this in turn increases their happiness. 
In this paper I will argue that Leibowitz's account of how friendship contributes to happiness is mistaken. In what follows I will first present Leibowitz's view, and then argue against it. I have two main worries with his account. One worry is that increase in self-worth is not characteristic of friendship and hence it is problematic to use it for explaining the connection between friendship and happiness. The other worry is that the distinctive way in which increase in selfworth contributes to happiness seems to be in an important way different from the distinctive way in which friendship contributes to happiness. Finally, I will point to what I take to be the right direction in explaining the connection between friendship and happiness.

\section{Leibowitz's account of friendship}

Leibowitz's strategy for explaining the contribution of friendship to happiness is to identify a 'distinctive' feature of friendship (Leibowitz 2018: 98) which would make the link between friendship and happiness something which is due to the 'very nature' of friendship (Leibowitz 2018: 100). Leibowitz is careful to not speak about essential or accidental properties of friendship, and points out that by distinctive feature he has in mind features which are characteristic of prototype friendships (Leibowitz 2018: 114).

The characterisation of friendship Leibowitz adopts is it being a 'relationship between two people in which each participant values the other and successfully communicates this fact to the other' (Leibowitz 2018: 101). One feature of this characterisation is that friendship is reciprocal. Although it is arguable that friendship need not be such (Rorty 1987; Sherman 1993) it seems common sense that the paradigmatic examples of friendship are indeed cases where friendship is mutually acknowledged and reciprocal. The other feature of this characterisation is that in friendship each of the friends values the other. This seems right: it is clear that friends value each other in some way. However, as I will suggest shortly, Leibowitz's account suffers in that it does not discuss in more detail what the valuation of a friend involves. Finally, the third feature in Leibowitz's characterisation of friendship is the suggestion that the friends' valuations need to be communicated successfully between the two friends. One might worry that this feature is too restrictive, 
as it is not clear whether communication of valuation happens often in friendship. However, Leibowitz adopts a broad view of what communication of value is, suggesting that it is not restricted to instances of explicit communication of this valuation, but rather is something that happens through shared activities. ${ }^{1}$ Hence it seems unlikely that this feature of Leibowitz's account would be too restrictive.

In fact, I would argue that Leibowitz's characterisation of friendship is if anything insufficiently restrictive. Many relations that we would not consider friendships satisfy the characterisation he offers. For example, business partners can value each other and successfully communicate this fact to each other without being friends; so too can colleagues, members of a sports team, family members who are not friends, and others. Therefore, Leibowitz's characterisation of friendship falls short of picking out that which is distinctive about friendship as opposed to a broader set of relations. Although he seems to consider this objection, his reply betrays that he hasn't fully grasped it: "the force of the objection, I suspect, comes from the fact that we may tend to introduce a colleague as "a colleague" rather than a "friend"' (Leibowitz 2018: 115) even in the cases where this colleague is an actual friend. If that were where the force of the objection was coming from, then indeed the objection would be one about labels, and one to be easily dealt with. However, it is not the linguistic point that makes the objection powerful, but the fact that we simply do value and successfully communicate this value to many people besides our friends. Our friendships are just a subset of this broader set of relations and hence the characterisation of friendship Leibowitz offers is not specific enough to help us pick out what is distinctive about friendship as opposed to other relations.

I would suggest that in order to narrow things down in such a way as to find a truly distinctive characteristic of friendship, one has to say more about what is involved in the particular valuation pertaining to friendship. It seems to me that this will be key to being able to differentiate between, for example, a business partnership and a friendship. To illustrate how specifying a particular kind of valuing

\footnotetext{
1 'We should note that the communication of valuing between friends is characteristically performed in, and by way of, shared activities' (Leibowitz 2018: 107).
} 
might be used to pick out different sets of relations, consider the distinction between instrumental friendships and friendships where the other is valued for their own sake. For example, Aristotle contrasts a higher, nobler type of friendship — what he calls 'virtue' friendship (but is also in the literature referred to as 'companion' or 'character' friendship (Cooper 1980) in order to remind us that the agents needn't be perfectly virtuous) — with two more basic kinds of friendship, utility friendship and pleasure friendship. The latter two are instrumental friendships. What distinguishes virtue friendship from instrumental friendship is that in the former the friend is valued for their own sake, whereas in utility and pleasure friendships the friend is valued only in so far as they provide utility or pleasure. ${ }^{2}$ Hence the instrumental friendship dissipates the moment the utility or pleasure is gone whereas virtue friendship is more lasting. Aristotle's account is an example of how specifying a particular kind of valuing - namely, valuing the other for their own sake - can help us pick out a particular set of relations, in this case what Aristotle considered to be the higher type of friendship. Similarly, specifying a particular type of valuing could help us pick out what is distinctive about friendship as opposed to other relations, such as business partnership. With this caveat in mind let me proceed to the main point of the paper which is the explanation of the link between friendship and happiness.

Leibowitz explains the connection between friendship and happiness with an increase in one's sense of self-worth that occurs because of friendship. His claim is that the successful communication of value between friends increases the friends' sense of self-worth, and this contributes to their happiness: 'friendship contributes to each friends' sense of self-worth, which, in turn, impacts on each friend's happiness' (Leibowitz 2018: 115).

Below I will argue that Leibowitz's proposal is mistaken. It seems to me the wrong picture of friendship to explain the link between friendship and happiness via an increase in one's sense of self-worth (Leibowitz 2018: 101). Whereas it is true that an increase in a sense

${ }^{2}$ Aristotle, Nicomachean Ethics, 1156a13-18: 'So those who love for what is useful have a liking based on what is good for themselves, and those who love for pleasure have a liking based on what is pleasant to themselves, and the other person is loved not for what he is, but insofar as he is useful or pleasant.' 
of self-worth might contribute to happiness, I don't think that this is the same as the distinctive contribution of happiness caused by friendship. Second, it is not clear to me that there is an intimate connection between friendship and an increased sense of self-worth to begin with. As I will try to show, speaking about a sense of selfworth seems to be at best a needless detour, and at worst, a move that turns the value of friendship on its head.

\section{Methodological issue. What kind of friendship are we interested in explaining?}

Before I proceed to the counterargument, let me deal with a methodological issue. The set of friendships is large and diverse, there is a great variety of things we refer to as friendships. For example, there are better friendships (such as an Aristotelian virtue friendship) and lesser friendships (such as drinking buddies). When we go below the surface of appearance, the latter seem to bear so little resemblance to the former, that it is a valid philosophical worry whether one can capture the two in one and the same account at all. One might take it to be the case that good friendships are the focal point of all friendship. ${ }^{3}$ However, it is possible to deny this, and argue that when we speak about friendship, we are speaking about too diverse a set of relations and what we say about good friendship need not inform discussion of all friendship. Hence a valid question to ask is: what is the set of things we are interested in providing an account for?

What I will be interested in here is instances of friendship in which we value the other for their own sake. We already saw that in Aristotle's account this valuation of the other for their own sake is what distinguishes virtue friendship from instrumental friendship. However, I won't speak here about virtue friendship in order to avoid any extra theoretical baggage coming with Aristotle's particular account. I simply want to focus on the valuation of the other for their own sake, and for this purpose will borrow a definition from Badhwar and refer to the friendships I am interested in as 'end

${ }^{3}$ This is what Aristotle's strategy is when he identifies virtue friendship to be the focal point of all friendship. Aristotle, Nicomachean Ethics, 1157a25-1157b5. 
friendships'. ${ }^{4}$ I am interested in end friendships because friendship where we care for the other for their own sake seem to be the prime example of friendship (Hitz 2011). Common sense would concur: it is not unusual to say of someone who doesn't instantiate the characteristics of a good friend (e.g. they are not interested in you for your own sake, but just for the entertainment you provide them with) that they are not 'real friends'. This common parlance suggests that we tend to think of end friendship not only as an example of a better friendship, but also as a better example of friendship, in the sense of being most friendship-like of all friendships.

Further, I focus on end friendship because I expect that it is in these instances of friendship that friendship's distinctive contribution to happiness is most likely to be clearly exemplified. Hence I take it that end friendship should ideally be the focus of our discussion when we provide an account of how friendship contributes to happiness.

This is not to say that other friendships don't contribute to happiness. We tend to think that all friendships contribute to happiness, in some way. Hence one might worry that, if end friendship has very little in common with other friendship, perhaps what contributes to happiness in end friendship is not just a clearer and more intense exemplification of what contributes to happiness, in a smaller measure, in all friendships. Perhaps it is just a qualitatively different thing. And if so, providing an account of what contributes to happiness in the case of end friendship might leave us without answer to the question of what contributes to happiness in other friendships. I am prepared to accept that, since I am interested in providing an answer to what makes end friendship contribute to happiness. Because of the possibility that end friendships and other friendships might turn out to be relations too different to be well captured by the same account, this will leave open the question of whether and to what extent what I will argue for will apply to other friendships too.

From now on, in arguing against Leibowitz, I am proceeding on the assumption that what he is trying to do in his paper, is to give at

\footnotetext{
4 'an end friendship is a relationship in which one loves and cares for the friend as the person she is, and as an essential part of one's ends, and not wholly, or even primarily, as a means to independently defined ends' (Badhwar 1993: 3; see also Badhwar 1987).
} 
least partial explanation of what makes end friendship contribute to happiness. Hence, it is possible that Leibowitz could respond to my objections by claiming that his account only applies to instances of instrumental friendship. Even though I think my criticism could in principle be extended and used to argue against Leibowitz's account even in cases of instrumental friendship, this is beyond the scope of the present paper. I will here be interested in showing that Leibowitz's account doesn't apply to end friendships.

From now on, when I speak about friendship, I will have in mind end friendship. I will argue that when we seek to explain what makes end friendship contribute to happiness, Leibowitz's account is inadequate, and we have to give a different account of the link between friendship and happiness.

\section{Friendship happiness is not self-worth happiness}

I will now argue that it is wrong to put the emphasis on self-worth in order to explain how friendship contributes to happiness. I will argue against the claim that it is the increase in self-worth caused by friendship which explains why friendship contributes to happiness.

I will argue for two things in order to show that this claim is implausible. First, I will argue that whereas friendships might indeed be accompanied by an increase of self-worth, this by no means needs to be the case, and hence an increase in one's sense of self-worth is not characteristic of the friendship relation. Then I will argue that any increase of self-worth in friendship fails to explain the specific way in which friendship contributes to happiness. Hence even if my first claim was challenged and an increase in one's sense of self-worth turned out to be intimately related to friendship, there are still other features of friendship that better explain why friendship contributes to happiness.

\subsection{Increase in one's sense of self-worth is not characteristic of friendship}

To accept Leibowitz's account of how friendship contributes to happiness, we would need to ground the claim that an increase in our 
sense of self-worth is characteristic of friendship. However, as I will now argue, this does not seem plausible.

Leibowitz justifies his move with the psychological observation that we tend to value more those things that we perceive others as valuing. His point is that since in friendship we perceive our friend valuing us, we tend to value ourselves more on that account: 'recognising that others value our own lives may impact on our sense of self-worth' (Leibowitz 2018: 101). It may, but it need not. In order to ground friendship's contribution to happiness on an increase in our sense of self-worth we need more than a weak connection between the two.

It seems implausible to consider an increase in one's self-worth to be characteristic of friendship, because a lot of friendships are not accompanied by such an increase. Here it might help to distinguish between two meanings of a sense of self-worth: (i) a sense of oneself as a source of valuable experiences to others, and (ii) a sense of one's life as valuable in and of itself. ${ }^{5}$

When taken to mean the first, it seems hard to deny that friends can and often do influence our sense of self-worth. They might cause us to increase the worth we put on certain skills we have, or even of certain features of ours. I might value my own writing more if a friend of mine enjoys my stories, or my sense of humour more if my friend actually laughs at my jokes. However, we shouldn't assume friendship is usually going to result in an increase in this sense of selfworth. Maybe I think that my jokes are terrific, but my friend lets me know that they aren't. My sense of self-worth could go down in this case. It seems that friendship is more than a mutual admiration society; friends are not only going to boost your self-worth, but also shower you in cold water when you need it.

It does seem, in any case, that Leibowitz has the second meaning of a sense of self-worth in mind. However, I would argue that self-worth understood in this way is unlikely to be influenced by friendship, at least not to an extent that would justify drawing a connection between a boost in one's sense of self-worth and friendship. First, there are too many friendships which would not result in such a boost; in particular friendships between people with a decent amount of self-worth are unlikely to be accompanied by an increase

${ }^{5}$ Thanks to an anonymous reviewer for suggesting this distinction. 
in one's sense of self-worth. An example of this would be the virtuous person. The virtuous person has a high sense of self-worth because of their virtues. Such people are unlikely to rely on others' recognition in order to build their own sense of self-worth. E.g. in the Analects, Confucius 'warns that the exemplary person does not measure his standing or significance in terms of the recognition or esteem he has won from others' (Luo 2019: 55).

Second, there is a distinctive sense in which my sense of selfworth shouldn't be easily affected by others' evaluations of me and should be a more robust and stable appreciation of myself. My own sense of self-worth is something so fundamental to me it would seem off to allow it to fluctuate depending on other people's evaluations. For example, we would think that something has gone badly wrong if my self-worth goes down just because I have no friends who value me. Similarly, there is something going wrong if my self-worth goes up for no merit of my own, but just because I have many friends who value me. Considering the opposite case, perhaps it is true that, if I have an extremely low sense of self-worth, any decent friendship is going to result in my increasing it. But this seems to be a case in which something has gone badly wrong with me to begin with, and we shouldn't use this case to infer what is characteristic of friendship. In a similar way, if I happen to suddenly go bankrupt, we would expect a friendship to result in my having enough money at least to eat. However, to infer from this that financial help is characteristic of friendship would be a mistake.

Hence, it seems implausible that an increase in one's sense of self-worth in the second sense would be something characteristic of friendship. Leibowitz holds that a feature cannot be essential to friendship if it is not uncommon for friendships to lack this feature. ${ }^{6}$ As I argued, it is not obvious that our sense of self-worth would be significantly influenced by friendship, hence friendship is not well characterised by an increase in our sense of self-worth.

Now I will turn to the second issue. It is not clear how a potential boost in one's sense of self-worth could help explain the increase in happiness of the kind observed in friendship.

${ }^{6}$ This is evidenced in his rebuttal of Cocking and Kennett's account of friendship (Leibowitz 2018: 111). 


\subsection{Desire for friends vs desire for self-worth}

For the sake of argument in this and the following section I will assume that an increase in one's sense of self-worth (understood in the second sense above) is characteristic of friendship. Leibowitz takes the increase in one's sense of self-worth to explain the distinctive contribution to happiness that friendship gives rise to. ${ }^{7}$ This is a rather strong claim that I will now argue against. My claim is that the happiness caused by an increase of self-worth is not friendship's distinctive contribution to happiness.

One way to defend this is to relate happiness caused by friendship to the reason we find friendship desirable. It is plausible to suggest that the two have a lot in common, or even that they are often the same thing. If I want to have friends because I don't want to be alone, then it seems reasonable to suggest that not being alone is what makes me happy, and that it is a good candidate of what contributes to happiness in friendship. When asked why we desire friendship, a lot of things could come to mind, such as: not being alone, having a hand to help us, sharing pleasant moments, and many others. However, increasing our sense of self-worth doesn't seem like an obvious candidate for what we would say or even think of when we are asked why we desire friendship. When we desire friends what we seem to desire is different from desiring an increase in our sense of self-worth. Hence if what causes happiness in friendship is a thing we should be able to recognise as something that we desire when we desire friendship, an increase in our sense of self-worth cannot be what causes happiness in friendship.

But perhaps that which causes happiness in friendship isn't something that we desire when we desire friendship. Consider this analogy. Walking on the promenade makes me happy and I desire walking on the promenade because I enjoy looking at the sea. However, unbeknown to me, the fresh salty air I breathe while walking incurs health benefits and increases my happiness levels. So, the fresh salty air makes me happy. Similarly, perhaps I desire friendship because I

\footnotetext{
7 'And since one's happiness is sensitive to the degree to which one values one's own life, this account of friendship explains the intimate relationship between friendship and happiness' (Leibowitz 2018: 101).
} 
want to not be alone, but an increase in my sense of self-worth which I am not aware of boosts my happiness levels. It is possible that our happiness is boosted by things we are not aware of, and in general it is possible that we misidentify our reasons for being attracted to certain things.

However, even in this case it is also true that seeing the sea makes me happy, and not being alone makes me happy. In other words, the existence of a reason for my attraction that I am not aware of doesn't in and of itself preclude it from being the case that the reason I am aware of is a real reason. So maybe there are two sets of reasons we desire friendship - one that we are aware of (I want to not be lonely), and one that we aren't (an increase in self-worth).

I take it that when asking the question of why we desire friendship, we are mostly interested in an answer of the first kind - in a set of reasons that we are aware of and we can point to. If an answer can be offered to why we seek out friendship, which involves something that we are aware of, and actively desire, when we want friendship, this would make it a better answer to our question than an answer which doesn't. An explanation which involves more familiar reasons to seek out friendship (such as not wanting to be alone) will have stronger appeal than one that involves an increase in one's sense of self-worth.

Our desire for friendship seems to be independent from our desire to have a high sense of self-worth. Hence satisfaction of the former desire must result in a contribution to happiness which is different from the contribution to happiness resulting from a satisfaction of the latter desire. If we try to explain friendship happiness primarily with the happiness caused by a high sense of self-worth, we will be failing to capture the most distinctive way in which friendship contributes to happiness.

\subsection{Self-worth happiness is different from friendship happiness}

My third argument that friendship happiness is not brought about by an increase in one's sense of self-worth has to do with the following observation. A contribution to one's happiness caused by an increase of self-worth is markedly different from the distinctive contribution to one's happiness caused by friendship. 
Leibowitz suggests that the happiness caused by friendship is somehow substitutable with the happiness caused by self-worth: 'friendship might not be necessary for happiness as long as one can obtain a sufficiently high sense of self-worth through other venues' (Leibowitz 2018: 115). However, common sense here, I think, goes against Leibowitz's intuition. The happiness caused by friendship is simply not interchangeable with the happiness caused by an increase in self-worth. It seems more plausible to think that whereas one can indeed reach a high level of happiness even without friendship, were one to subsequently enter a good friendship, this would further increase one's happiness by adding a dimension to one's life that is only achievable via friendship. Assuming the contrary would simply not explain why people who already have all other sources of happiness, including a high sense of self-worth, seek friends and seem to be missing a distinct source of happiness if they have none. Friends delight at, and actively seek, the opportunity to share parts of their life with each other, including when they are not in need of anything else. As Aristotle beautifully puts it in the Eudemian Ethics:

For when we are in need of nothing then everyone seeks people to indulge with $[\ldots]$ and we most need friends worth living with. ${ }^{8}$

Hence it seems that the distinctive contribution of friendship to happiness is quite separate from the contribution to happiness caused by an increase in one's sense of self-worth.

Another consideration in favour of this is the fact that friends are not fungible: they cannot be exchanged with something else to get the same value (Helm 2009; Millgram 1987). The non-fungibility of friends also suggests that one cannot replace friendship with something else and expect to reap the same sort of happiness. The happiness coming from friendship doesn't seem to be interchangeable with the happiness coming from an increase in self-worth which is brought about by a friend. There is something importantly different in the happiness caused by friendship.

In support of this point comes the fact that one can have a high sense of self-worth and still be unhappy if one doesn't have friends. A lot of people would think that, despite all other goods and all

${ }^{8}$ Aristotle, Eudemian Ethics, 1244b16-20. 
self-worth they have, a life with no friends for them would be an unhappy life. Happiness caused by friendship goes over and above that caused by self-worth. For many it is true that no matter how high one's sense of self-worth, if one is unlucky in that one doesn't have friends, one cannot be perfectly happy. This only makes sense if the happiness friendship offers is distinct from the happiness offered by a high sense of self-worth. To conflate the happiness of self-worth with that of friendship, as Leibowitz does, seems to be a gross mistake.

Another observation to illustrate the point is that one would not have a diminished self-worth just because they had moved to a new place or had been unlucky and had not yet made any friends. There is a distinctive sense in which friendship, even if it is something that we strive for and can bring about, also is something that 'happens' to us and is to an extent outside of our control (Thomas 1993: 53) so we might be unlucky and not have friends. If this is the case, there is a definite sense in which I would not be able to be as happy as I would if I had friends. However, there is not a sense in which my self-worth would not be as high as it would be if I had friends. Comparable is the case of a romantic partner: if I have not been lucky to meet a partner that values me in the right way, it is not my self-worth that is suffering because of this. My happiness certainly is suffering, but not my self-worth. My self-worth does not, and better not be, influenced, by this bad luck. Indeed, we would be concerned about someone whose self-worth was affected negatively in this case and would think they are making a mistake to let their self-worth be influenced in this way. The exact same thing goes with friendship. Whether I do or do not have a friend is unlikely to affect my self-worth. ${ }^{9}$ By contrast, whether I do or do not have friends seems to be something that would affect my happiness levels (Sherman 1993). Hence the specific contribution to happiness that is caused by friendship is different from the specific contribution to happiness related to a boost in one's sense of self-worth.

\footnotetext{
${ }^{9}$ See also discussion in 4.1.
} 


\section{Happiness and valuing our friends}

I suggest that instead of discussing self-worth, a more promising direction for explaining friendship's distinctive contribution to happiness is to concentrate on the value our friends have for us. Friendships usually provide us with various sources of happiness, such as utility and pleasure, however utility and pleasure are achievable via other means, e.g. by accumulating wealth and purchasing entertainment. What makes friendship special is that it involves a person in our life whom we value, and who values us. I suspect that the distinctive contribution of friendship to happiness is related to this appreciation of having someone special in our life: we are happy precisely because a person that we value is a part of our life. I take it that there is a direct link between attainment of something one values and increased levels of happiness; the fact that the thing is of value means that the attainment of that thing contributes to one's happiness. In the case of friendship, we value a person, and the fact that this person plays a special part in our life makes us happy.

As already mentioned above, I take it that the value of one's friend is intrinsic and irreducible; I cannot replace my friend with something else that I would value the same way. To take one of the bestknown examples of friendship in the literature, I take it that what Achilles lost when Hector killed Patroclus was not just a source of increase in his self-worth. He lost something of intrinsic and irreducible value to him - his friend's life. It is far more plausible to hold that this motivated his revenge, rather than considerations of his own loneliness or decrease in self-worth. I think that in order to explain the link between friendship and happiness a more fruitful direction of research would be to explore this notion of having someone in our life that we value for their own sake.

Providing a full account of how friendship contributes to happiness is a project for a separate paper. For now, it suffices to make the negative claim that friendship happiness is a different kind of happiness than the happiness caused by any utility, pleasure, or a sense of self-worth our friend might provide. 


\section{Conclusion}

Leibowitz claims to have explained the link between friendship and happiness. While I consider plausible his suggestion that the communication of valuing between two friends might be related to an increase in happiness, I disagree with his proposal that what explains friendship happiness is the increase in one's sense of self-worth. This proposal seems at best restricted to only special cases of instrumental friendship, and at worst incompatible with the non-instrumental nature of valuing our friend in end friendships. Leibowitz's suggestion that Aristotle meant to say that "no one would choose to live without a minimal sense of self-worth' (Leibowitz 2018: 116) when in fact he said that no one would choose to live without friends,${ }^{10}$ is a clear pointer to the gross underestimation of the value of friendship that goes on in Leibowitz's account. If this were what Aristotle 'should have said' (Leibowitz 2018: 116) it is not clear why would anyone of the vast majority of people who already have at least a minimal sense of self-worth, want friendship. I hope with this paper to have shown that providing an account of the link between friendship and happiness in which an emphasis on one's sense of self-worth plays the central role, is as serious an understatement of the value and beauty of friendship as any other.

Diana Sofronieva

Independent researcher diana.sofronieva@gmail.com

\section{References}

Annas, Julia. 1977. Plato and Aristotle on friendship and altruism. Mind 86(344): 532-54.

Aristotle. Nicomachean Ethics. Translated by Joe Sachs. Hackett Publishing Company, 2009.

Aristotle. The Eudemian Ethics. Translated by Peter L. P. Simpson. Transaction Publishers, 2013.

Badhwar, Neera Kapur. 1987. Friends as ends in themselves. Philosophy and Phenomenological Research 48(1): 1-23.

${ }^{10}$ The line in the Nicomachean Ethics reads: 'no one would choose to live without friends, despite having all the rest of the good things'. 1155a2-3. 
Badhwar, Neera Kapur. 1993. Friendship: A Philosophical Reader. Ithaca, N.Y.: Cornell University Press.

Cooper, John. 1980. Aristotle on friendship. In Essays on Aristotle’s Ethics, ed. by Amélie Oksenberg Rorty. University of California Press.

Helm, Bennet W. 2009. Love, Friendship, and the Self. Oxford University Press.

Hitz, Zena. 2011. Aristotle on self-knowledge and friendship. Philosopher's Imprint 11(12): 1-28.

Leibowitz, Uri D. 2018. What is friendship? Disputatio 10(49): 97-117.

Luo, Shirong. 2019. Happiness and the good life: a classical Confucian perspective. Dao 18(1): 41-58.

Millgram, Elijah. 1987. Aristotle on making other selves. Canadian Journal of Philosophy 17(2) 361-76.

Rorty, Amelie Oksenberg. 1987. The historicity of psychological attitudes: Love is not love which alters not when it alteration finds. Midwest Studies in Philosophy 10(1): 399-412.

Sherman, Nancy. 1993. Aristotle on the shared life. In Friendship: A Philosophical Reader, ed. by Neera Kapur Badhwar. Cornell University Press.

Thomas, Laurence. 1993. Friendship and other loves. In Friendship: A Philosophical Reader, ed. by Neera Kapur Badhwar. Cornell University Press. 